\title{
A SHORT STAY UNIT DECREASED MEAN LENGTH OF STAY IN A HOSPITAL IN SOUTH BRAZIL
}

\author{
Tania Weber Furlanetto1,2,3, Daniel de Souza Barcelos ${ }^{1}$, Gustavo \\ Adolpho Moreira Faulhaber ${ }^{1,4}$
}

\begin{abstract}
Introduction Public health services in Brazil are periodically overcrowded. Since reducing the length of stay (LOS) could increase the availability of hospital beds, this study evaluated the impact of a short stay unit (SSU) on LOS, early readmission rates, and intra-hospital mortality rates.

Methods Data were evaluated retrospectively in the 12 months before and after the establishment of a multidisciplinary SSU in a tertiary care hospital in south Brazil. All admissions of adult patients through the Emergency Department for causes in nine groups of the World Health Organization International Code of Diseases-10 were included.
\end{abstract}

Results Mean LOS decreased 1.42 days in the first year after the implementation of a SSU with no change in 7-day readmission rates or intra-hospital mortality rates. This decrease may be partially explained by the decrease in the mean LOS in other areas of the hospital, although the amount of hospital-bed days saved in the second year was 5,668 days in the Internal Medicine Division and 1,595 days in all other clinical or surgical areas. Mortality rates after discharge were not evaluated.

Conclusions A SSU decreased mean LOS of selected patients admitted through the Emergency Department without increasing 7-day readmission rates or intra-hospital mortality.

Keywords: Health care surveys; quality improvement; length of stay

Higher life expectancy and better management of chronic conditions have caused an increased demand for health services in Brazil. Bed shortage is common ${ }^{1}$ and emergency rooms are often overcrowded ${ }^{2}$.

In the Hospital de Clínicas de Porto Alegre, a tertiary care, academic, public hospital in south Brazil, patients are admitted majorly through the Emergency Department, and their data are registered in electronic files. When admission to hospital is indicated, and there are no available beds in the inpatient area, patients stay in the Emergency Department until discharge.

During the epidemics of H1N1 influenza in 2009, a multidisciplinary short stay unit (SSU) was implemented in the Internal Medicine Division, with criteria for early discharge of convalescent patients. Patients had a low mean length of stay (LOS), and no one needed early readmission (unpublished data). Based on these results, a SSU with 18 beds was created in the Internal Medicine Division to treat acute clinical patients and to allow for early discharge of convalescent patients. As decreased LOS could be associated with worse outcomes, including early readmission rates, the aim of this study was to evaluate the impact of the SSU on LOS, early readmission rates, and intrahospital mortality rates.

\section{METHODS}

Our study was conducted at HCPA, a large public hospital in south Brazil, which has an Internal Medicine Division with approximately 100 beds for inpatients.

Clin Biomed Res. 2014;34(4):381-386

1 Programa de Pós-Graduação em Medicina: Ciências Médicas, Universidade Federal do Rio Grande do Sul (UFRGS). Porto Alegre, RS, Brazil.

2 Serviço de Medicina Interna, Hospital de Clínicas de Porto Alegre (HCPA). Porto Alegre, RS, Brazil.

3 Pesquisadora do CNPq. Porto Alegre, RS, Brazil.

4 Faculdade de Medicina, Universidade Federal do Rio Grande do Sul (UFRGS). Porto Alegre, RS, Brazil.

Corresponding author: Tania Weber Furlanetto E-mail: taniafurlanetto@gmail.com Serviço de Medicina Interna, Hospital de Clínicas de Porto Alegre

Rua Ramiro Barcelos, 2350/700 90035-903, Porto Alegre, RS, Brasil 
Data were obtained using in-house software. The groups of diseases that caused the greatest number of admissions to the SSU were selected, according to the World Health Organization International Code of Diseases-10: influenza and pneumonia (J09-J18); chronic lower respiratory diseases (J40-J47); other diseases of urinary system (N30-N39); other forms of heart disease (I30-152); cerebrovascular diseases (I60-169); human immunodeficiency virus disease (B20-B24); malignant neoplasms of digestive organs (C15-C26); other bacterial diseases (A30-A49); and diabetes mellitus (E10-E14). All admissions through the Emergency Department due to these diseases in two years were included: before (December 1, 2008-November 30, 2009) and after the establishment of the SSU (December 1, 2009- November 30, 2010). When hospital beds were available, patients were transferred to the Internal Medicine Division or any other clinical or surgical area of the hospital, or they remained in the Emergency Department until discharge.

The SSU had 18 beds, 9 for each sex. Patients were treated by two teams; each team included one senior internist, two resident physicians, and two medical students. When the emergency physicians, in the first evaluation, believed a patient had an acute condition that would require hospitalization for ten days or less, he/she was admitted, if there was a bed available, to one of the two teams, which cared for nine patients each. After admission to the SSU, patients were evaluated by a nurse, and subsequently by a medical resident or medical student, who collected data and formulated the investigation, treatment, and discharge plans. If social problems were identified, which could hinder the discharge process, an early intervention of the social services was requested. There were two medical rounds a day, coordinated by one senior internist (at least once a day) or a second- or third-year medical resident. Every day there was also a short round including nurses, social work assistants, psychologists, dietitians, pharmacists, and managers, for problem solving to decrease the LOS. Outpatient follow-up in the first 7 days after discharge was available if needed.

The primary outcomes were LOS as the primary efficiency outcome and 7-day readmission rates ${ }^{3}$ and intra-hospital mortality rates as safety endpoints. The mean LOS was calculated for patients discharged alive.

This study was approved by the Health Research Ethics Board at the Hospital de Clínicas de Porto Alegre and the need for patient informed consent was waived.
Data were analyzed with the Mann-Whitney test or chi square test, as indicated, using the software SPSS $18.0 \circledast$ (Chicago, IL, EUA). Differences were considered significant when the two-sided $P$ value was less than 0.05 .

\section{RESULTS}

During the two years, 11,040 adult patients, 5,289 in the first and 5,751 in the second year, were admitted to the hospital through the Emergency Department. Admissions for diseases other than those previously mentioned were excluded (1,489 in the first year and 1,793 in the second year), so 7,758 admissions were evaluated: 2,129 to the Internal Medicine Division (779 in the first year and 1,350 in the second year), 2,500 to other hospital departments $(1,340$ in the first year and 1,160 in the second year), and 3,129 patients who remained in the Emergency Department until discharge $(1,681$ in the first year and 1,448 in the second year). These data are shown in Figure 1.

As expected, the proportion of patients admitted to the Internal Medicine Division with the selected diagnosis increased after the implementation of the SSU (before: $20.5 \%$, after: $34.1 \%, p<0.001$ ); a decrease in the proportion of patients remaining in the Emergency Department (before: $44.2 \%$, after: $36.6 \%, p<0.001$ ) or admitted to other areas (before: $35.3 \%$, after: $29.3 \%, p<0.001$ ) was also observed. These data are shown in Table 1.

There was a decrease in the mean LOS of all patients admitted to the hospital for the selected causes through the Emergency Department and discharged alive after the establishment of the SSU (before: $10.89 \pm 13.17$ days, after: $9.47 \pm 11.24$ days, $p=0.006$ ), as well as a marked decrease in the LOS of patients admitted to the Internal Medicine Division [before $(n=680)$ : $14.33 \pm 14.57$ days, after $(n=1243)$ : $9.77 \pm 10.62$ days, $p<0.001]$ and to other hospital departments [before $(n=1,142): 18.95 \pm 15.22$ days, after $(n=938): 17.25 \pm 14.23$ days, $p=0.014]$. Conversely, mean LOS did not change for patients remaining in the Emergency Department [before $(n=1,547)$ : $3.42 \pm 2.21$ days, after $(n=1,310): 3.61 \pm 2.61$ days, $p=0.856]$. These data are shown in Figure 2. The number of hospital-bed days saved in the second year was 5,668 days in the Internal Medicine Division and 1,595 days in other clinical or surgical areas.

There was no change in the intra-hospital mortality rates of all patients admitted for the selected causes [before $(n=3,800): 11.3 \%$, after $(n=3,958): 11.8 \%$ $\mathrm{p}=0.53$ ] or in their 7-day readmission rates [before $(n=3,369): 7.2 \%$, after $(n=3,491): 6.7 \%, p=0.41]$ after the implementation of the SSU. 


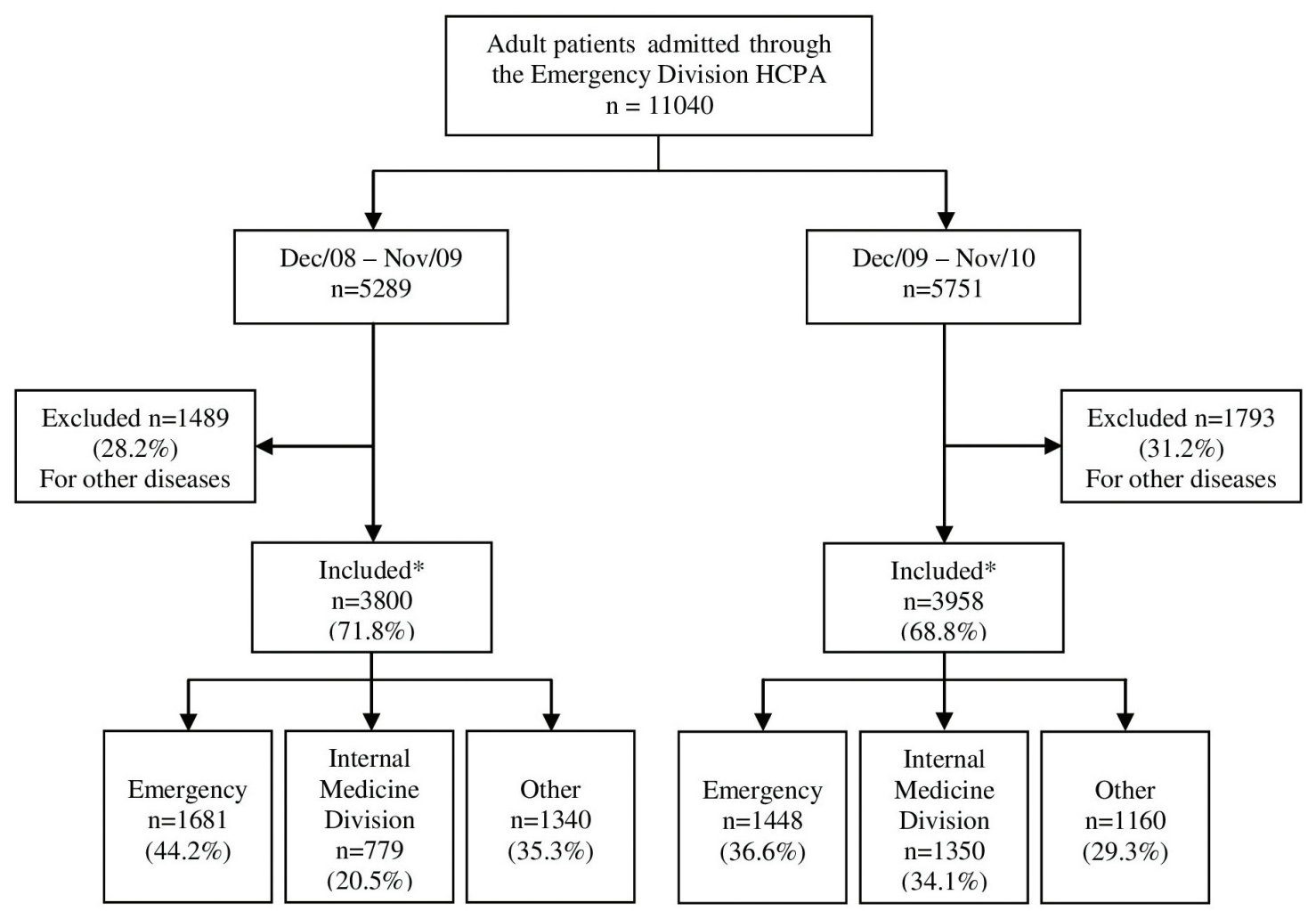

Figure 1: Study flow diagram. *Admissions due to diseases in the following groups of the WHO ICD-10: J09-J018: influenza and pneumonia, J40-J47: chronic lower respiratory diseases, N30-N39: other diseases of urinary system, I30-I52: other forms of heart disease, I60-I69: cerebrovascular diseases, B20-B24: human immunodeficiency virus disease, C15-C26: malignant neoplasms of digestive organs, A30-A49: other bacterial diseases, and E10-E14: diabetes mellitus. Emergency: patients remaining in the Emergency Department for more than 24 hours until discharge; Others: other clinical or surgical areas; HCPA: Hospital de Clínicas de Porto Alegre.

Table 1: Selected causes* of adult patients admission, before (12/01/2008-11/30/2009) and after (12/01/2009-11/30/2010) the implementation of a short stay unit in the Internal Medicine Division, according to the admission area.

\begin{tabular}{lccc}
\hline & $\begin{array}{c}\text { December 1, 2008-November } \\
\text { December 1, 2009-November }\end{array}$ & $\mathbf{p}$ \\
& $\mathbf{3 0 , 2 0 0 9}$ & $\mathbf{3 0 , 2 0 1 0}$ & $\mathbf{n}(\mathbf{\%})$ \\
\hline All & $3,800(100)$ & $3,958(100)$ & $<0.001$ \\
Emergency & $1,681(44.2)$ & $1,448(36.6)$ & $<0.001$ \\
Internal Medicine & $779(20.5)$ & $1,350(34.1)$ & $<0.001$ \\
Other clinical or surgical areas & $1,340(35.3)$ & $1,160(29.3)$ & \\
\hline
\end{tabular}

*Groups J09-J018, J40-J47, N30-N39, I30-I52, I60-I69, B20-B24, C15-C26, A30-A49, and E10-E14, of the WHO ICD-10. Emergency: patients remaining in the Emergency Department for 24 hours or more until discharge

\section{DISCUSSION}

In this study, mean LOS of patients admitted to a tertiary care hospital through the Emergency Department with selected diagnosis decreased 1.42 days in the year following the implementation of a SSU in the Internal Medicine Division, with no change in 7-day readmission rates or intra-hospital mortality rates. This decrease may be partially explained by the decrease in the mean LOS of patients admitted to other clinical or surgical areas of the hospital. The larger number of hospital-bed days saved in the Internal Medicine Division (5,668 days) as compared with the other areas (1,595 days) and the increase in the number of patients admitted to the Internal Medicine Division after SSU implementation indicate that the SSU contributed greatly to this decrease.

Several factors have been associated to a trend to decrease LOS, as the judicious use of diagnostic tests, allowing earlier and more precise diagnosis, more effective drugs and procedures, and others ${ }^{4-10}$. 


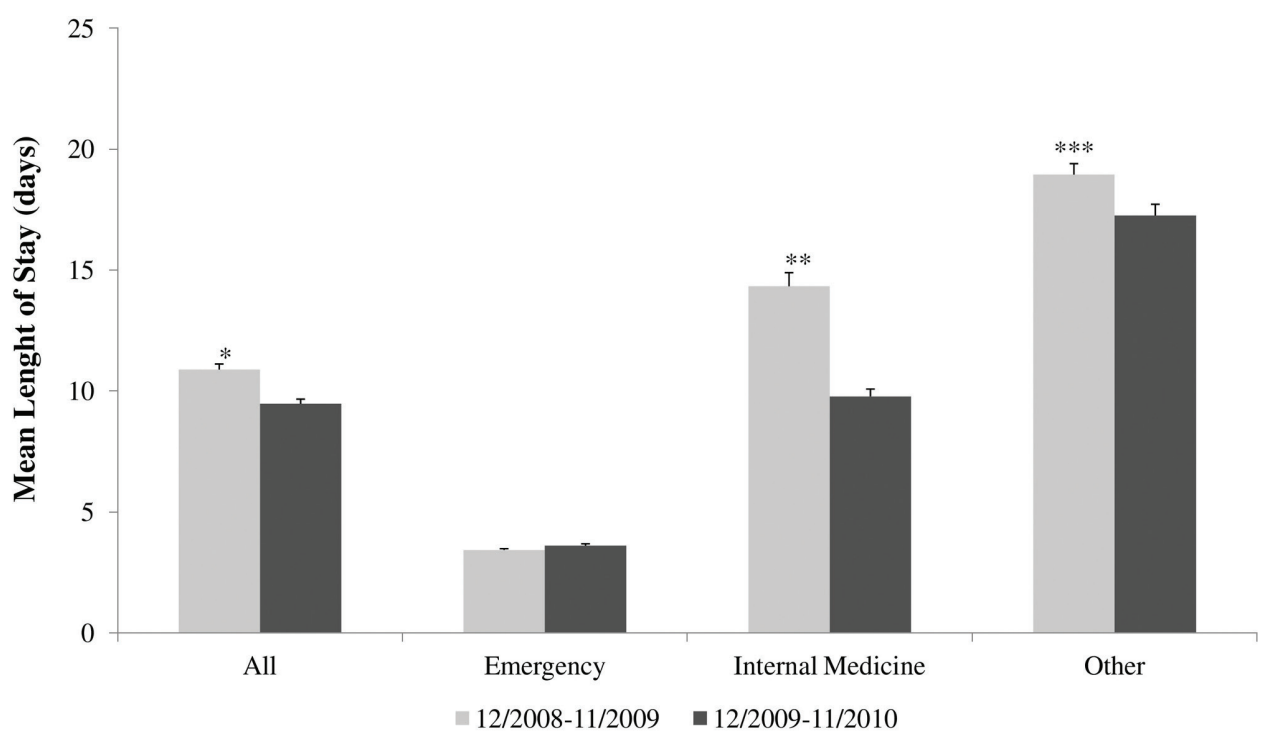

Figure 2: Mean length of stay of patients discharged alive after being admitted for selected causes (WHO ICD-10 groups J09-J018, J40-J47, N30-N39, I30-I52, I60-I69, B20-B24, C15-C26, A30-A49, and E10-E14) to a tertiary care hospital, before (December, 2008-November, 2009) and after (December, 2009-November, 2010) the implementation of a short stay unit in the Internal Medicine Division, according to the area of admission. Emergency: patients remaining in the Emergency Department for 24 hours or more until discharge; Others: other clinical or surgical area. The mean LOS was 10.89 days before and 9.47 days after the SSU implementation for all patients; 3.42 days before and 3.61 days after SSU implementation for patients in the Emergency Department; 14.33 days before and 9.77 days after the SSU implementation for patients in the Internal Medicine Unit; and 18.95 days before and 17.25 days after the SSU implementation for patients in other areas. Data are shown as mean \pm SE of the mean. ${ }^{*} p=0.006 ;{ }^{* *} p<0.001 ;{ }^{* \star *} p=0.014$.

The effect of interventions to decrease LOS has also been studied. Moher et al. randomized clinical patients to two groups: one received standard treatment, while the other had also a medical team coordinator, whose role was to facilitate administrative tasks such as discharge planning, to coordinate tests and procedures, and to collect and collate patient information. The authors observed a decrease in LOS, with no significant difference in the 14-day readmission rate ${ }^{11}$. In patients with pneumonia, the use of multidisciplinary rounds decreased LOS $^{12}$. Home treatment supported by respiratory nurses allowed early discharge of patients with acute exacerbations of chronic obstructive pulmonary disease uncomplicated by acidotic respiratory failure or other medical problems, with no increase in readmission, additional hospital days, and deaths within 60 days of initial admission ${ }^{13}$.

Lim at al. compared the effect of two discharge protocols on consecutive patients admitted for acute severe exacerbations of bronchial asthma after remission of signs and symptoms or after improvement but before complete remission of signs and symptoms. They concluded that the release of asthmatics who responded promptly to intensive treatment and were compliant with medication despite incomplete resolution of symptoms, signs and peak expiratory flow rates at the time of discharge from hospital, may not be associated with increased risk of early relapse ${ }^{14}$. Another study including patients with exacerbated chronic obstructive pulmonary disease, comparing early discharged patients with nurse supervision at home with those receiving the standard treatment, found no increase in the rate of hospital readmissions ${ }^{15}$. In a quasi-experimental study that compared usual care with usual care plus nurse practitioner/physician management of hospital care, multidisciplinary team-based planning, expedited discharge, and assessment after discharge, Cowan et al. observed a decrease in the LOS with no differences in mortality or 4-month readmissions ${ }^{16}$. Recently, McAlister et al. described the effect of an initiative comprising four actions (demand capacity realignment, team integration and culture change, implementation of best practices, and transition optimizations) on LOS, readmission rates, and intrahospital mortality, with substantial reductions in LOS without increasing post-discharge events ${ }^{17}$.

In our study, the decrease in LOS was probably the result of the combination of several actions: development of an investigation plan and establishment of treatment goals in the first 24 hours, review of 
clinical conditions and results of exams twice a day, early identification of psychosocial problems, actions of the multidisciplinary team to decrease LOS, as well as the availability of outpatient follow-up in the first 7 days after discharge.

Although our results are impressive, this study has some flaws: mortality rates after discharge were not evaluated, and the results were not adjusted for risk factors. Nevertheless, we tried to control for some of these factors, as well as seasonality of diseases, by including all the admissions during two whole years, the first one immediately before, and the second one immediately after the implementation of the SSU. Other limitations that could not be addressed were a change in pathogens causing infectious diseases in different years, as well as changes in medical residents working in the SSU.

In conclusion, a SSU in the Internal Medicine Division decreased mean LOS of patients admitted to the hospital for the selected diagnosis without increasing 7-day readmission rates or intra-hospital mortality.

\section{Disclaimer}

The authors had full access to and take full responsibility for the integrity of the data. The views expressed in this article are those of the authors and do not necessarily represent the views of the UFRGS and HCPA.

\section{Conflicts of interest}

All authors declare no conflict of interests.

\section{Funding}

Conselho Nacional de Desenvolvimento Científico e Tecnológico, CNPq, Brazil. Institution where the study was performed: Hospital de Clínicas de Porto Alegre, Brazil

\section{References}

1. Gonçalves EL, Dias MJM, Mattos HB. Assistência hospitalar no âmbito da previdência social no Estado de Sâo Paulo, Brasil. Rev Saude Publica. 1972;6(1):35-43. http://dx.doi.org/10.1590/S003489101972000100005 . PMid:4680260

2. Brick $A$. The stretchers from Emergency Room (ER. Rev Bras Cir Cardiovasc. 2009;24(1):101-2. PMid:19514120.

3. Heggestad T, Lilleeng SE. Measuring readmissions: focus on the time factor. Int J Qual Health Care. 2003;15(2):147-54. http://dx.doi. org/10.1093/intqhc/mzg019. PMid:12705708

4. Kaboli PJ, Go JT, Hockenberry J, Glasgow JM, Johnson SR, Rosenthal $\mathrm{GE}$, et al. Associations between reduced hospital length of stay and 30-day readmission rate and mortality: 14-year experience in 129 Veterans Affairs hospitals. Ann Intern Med. 2012;157(12):837-45. http://dx.doi. org/10.7326/0003-4819-157-12201212180-00003. PMid:23247937

5. Baker DW, Einstadter D, Husak SS, Cebul RD. Trends in postdischarge mortality and readmissions: has length of stay declined too far? Arch Intern Med. 2004;164(5):538-44. http:// dx.doi.org/10.1001/archinte.164.5.538. PMid:15006831
6. Harrison ML, Graff LA, Roos NP, Brownell MD. Discharging patients earlier from Winnipeg hospitals: does it adversely affect quality of care? CMAJ. 1995;153(6):745-51. PMid:7664228.

7. Cabre M, Bolivar I, Pera G, Pallares $\mathrm{R}$, Pneumonia Study Collaborative Group. Factors influencing length of hospital stay in communityacquired pneumonia: a study in 27 community hospitals. Epidemiol Infect. 2004;132(5):821-9. http://dx.doi. org/10.1017/S0950268804002651. PMid:15473144

8. Capelastegui A, España PP, Quintana JM, Gallarreta M, Gorordo I, Esteban C, et al. Declining length of hospital stay for pneumonia and postdischarge outcomes. Am J Med. 2008;121(10):845-52. http://dx.doi. org/10.1016/j.amjmed.2008.05.010. PMid:18823851

9. Bittar OJ. [Hospital productivity in the light of hospital indicators]. Rev Saude Publica. 1996;30(1):53-60. http://dx.doi.org/10.1590/S003489101996000100007. PMid:9008922

10. André C, Py MO, Mariño RG. [Causes of unjustified hospital stay following cerebral infarction]. Arq Neuropsiquiatr. 1997;55(3B):569-72. PMid:9629407.
11. Moher D, Weinberg A, Hanlon R, Runnalls K. Effects of a medical team coordinator on length of hospital stay. CMAJ. 1992;146(4):511-5. PMid:1737315.

12. O'Mahony S, Mazur E, Charney $P$, Wang $Y$, Fine J. Use of multidisciplinary rounds to simultaneously improve quality outcomes, enhance resident education, and shorten length of stay. J Gen Intern Med. 2007;22(8):1073-9. http://dx.doi.org/10.1007/s11606-0070225-1. PMid: 17486384

13. Cotton MM, Bucknall CE, Dagg KD, Johnson MK, MacGregor G, Stewart C, et al. Early discharge for patients with exacerbations of chronic obstructive pulmonary disease: a randomized controlled trial. Thorax. 2000;55(11):902-6. http://dx.doi. org/10.1136/thorax.55.11.902. PMid:11050257

14. Lim TK, Chin NK, Lee KH, Stebbings AM. Early discharge of patients hospitalized with acute asthma: a controlled study. Respir Med. 2000;94(12):1234-40. http://dx.doi. org/10.1053/rmed.2000.0958. PMid:11192961

15. Sala E, Alegre L, Carrera M, Ibars M, Orriols FJ, Blanco ML, et al. Supported discharge shortens hospital stay in patients hospitalized because 
of an exacerbation of COPD. Eur Respir J. 2001;17(6):1138-42. http:// dx.doi.org/10.1183/09031936.01.0006 8201. PMid:11491156

16. Cowan MJ, Shapiro M, Hays RD, Afifi A, Vazirani S, Ward CR, et al. The effect of a multidisciplinary hospitalist/ physician and advanced practice nurse collaboration on hospital costs. J Nurs Adm. 2006;36(2):79-85. http://dx.doi.org/10.1097/00005110200602000-00006. PMid:16528149

17. McAlister FA, Bakal JA, Majumdar SR, Dean S, Padwal RS, Kassam N, et al.
Safely and effectively reducing inpatient length of stay: a controlled study of the General Internal Medicine Care Transformation Initiative. BMJ Qual Saf. 2014;23(6):44656. http://dx.doi.org/10.1136/ bmjqs-2013-002289. PMid:24108415 